\title{
Increased intestinal glucose absorption and postprandial hyperglycaemia at the early step of glucose intolerance in Otsuka Long-Evans Tokushima Fatty Rats
}

\author{
Y. Fujita ${ }^{1}$, H. Kojima ${ }^{1}$, H. Hidaka ${ }^{1}$, M. Fujimiya ${ }^{2}$, A. Kashiwagi $^{1}$, R. Kikkawa ${ }^{1}$ \\ ${ }^{1}$ Third Department of Medicine, Shiga University of Medical Science, Shiga, Japan \\ ${ }^{2}$ Department of Anatomy, Shiga University of Medical Science, Shiga, Japan
}

\begin{abstract}
Summary Otsuka Long-Evans Tokushima Fatty (OLETF) rats are reported to be obese Type II (non-insulin-dependent) diabetic rats with insulin resistance and impaired insulin secretion. To investigate the contribution of intestinal glucose absorption to postprandial hyperglycaemia, we determined the plasma xylose concentrations after an $0.8 \mathrm{~g} / \mathrm{kg}$ oral xylose load which was used as a test of small intestinal glucose absorption in 6-week-old OLETF rats and weight-matched Long-Evans Tokushima Otsuka (LETO) rats. An oral glucose tolerance test showed that OLETF rats developed hyperglycaemia at 60 and 90 min after the glucose load, though the fasting plasma glucose concentration, insulin concentration and insulin-induced in vivo glucose utilization rate were similar. Consistently, in an oral D-xylose loading test, the peak concentration of plasma xylose in OLETF rats was increased by $58.7 \%$ compared with that of LETO rats $(p<0.005)$. The disappearance rate of plasma xylose concentrations after intrave-
\end{abstract}

nous xylose loading did not differ between the two strains. Co-treatment with $0.4 \mathrm{~g} / \mathrm{kg}$ phlorizin, a specific inhibitor of sodium-dependent glucose transporter 1 (SGLT1), abolished both plasma glucose and xylose concentrations after the loads. Morphological studies showed that both the small intestinal wet weight and surface area were $30 \%$ larger in the OLETF rats than in the LETO rats. Furthermore, the SGLT1 mRNA content of OLETF rats also increased compared with LETO rats. These results suggest that an increased SGLT1 expression concomitant with intestinal hypertrophy in OLETF rats is partly associated with postprandial hyperglycaemia before the onset of insulin resistance and hyperinsulinaemia. [Diabetologia (1998) 41: 1459-1466]

Keywords OLETF, xylose, SGLT1, intestinal hypertrophy, glucose absorption, postprandial hyperglycaemia.
Received: 27 April 1998 and in revised form: 20 July 1998

Corresponding author: H. Kojima, M.D., PhD., Third Department of Medicine, Shiga University of Medical Science, Seta, Otsu, Shiga, 520-2192, Japan

Abbreviations: OLETF, Otsuka Long-Evans Tokushima Fatty; LETO, Long-Evans Tokushima Otsuka; SGLT1, sodium-dependent glucose transporter 1; OGTT, oral glucose tolerance test; OXT, oral D-xylose loading test; IVXT, intravenous D-xylose loading test; GLUT, glucose transporter; PCR, polymerase chain reaction; GIR, glucose infusion rate; IRI, immunoreactive insulin; CCK, cholecystokinin; SSPI, steady-state plasma insulin; PBS, phosphate buffer saline; AUC, area under the curve.
Glucose intolerance is believed to be caused not only by insulin resistance but also impaired insulin secretion [1-3]. Dietary restrictions and exercise are effective in intervening in glucose intolerance, postprandial hyperglycaemia, and impaired insulin secretion $[4,5]$. $\alpha$-glucosidase inhibitors, which delay intestinal glucose absorption, also improve postprandial hyperglycaemia and hyperinsulinaemia in Type II (non-insulin-dependent) diabetic patients [6] and prevent the progression from impaired glucose tolerance to Type II diabetes [7]. We therefore hypothesize that increased intestinal glucose absorption may be another possible factor regulating postprandial hyperglycaemia in diabetes mellitus. 
Intestinal glucose absorption is thought to be regulated by the luminal absorptive surface area as well as the activity of sodium-dependent glucose transport at the apical membrane of the intestinal epithelia $[8,9]$. An increased dietary calorific as well as carbohydrate intake could induce expression of both sodium-dependent glucose transporter 1 (SGLT1) at the apical membrane and glucose transporter 2 (GLUT2) at the basolateral membrane of intestinal epithelial cells [8-11]. It has been reported previously that intestinal hyperplasia was observed in insulinopenic streptozotocin-treated diabetic rats with an increased intestinal glucose absorption [12-14]. Our recent study suggests that insulin could directly regulate intestinal epithelial cell growth [15].

Otsuka Long-Evans Tokushima Fatty (OLETF) rats, which were established as a genetic model of late-onset spontaneous obese Type II diabetes mellitus, show hyperglycaemia as well as insulin resistance and hyperinsulinaemia [16]. Hyperglycaemia, insulin resistance, and hyperinsulinaemia become remarkable after the age of 18 weeks or older. In the hyperinsulinaemic stage there are hyperplastic changes in the pancreatic islets. At 40 weeks of age, the pancreatic islet mass is decreased and replaced by connective tissues. The rats finally become hypoinsulinaemic and lose weight [16]. In interventional studies, not only spontaneous exercise [17] but also restriction of diet intake [18] at the early stage of diabetes improve insulin sensitivity and glucose intolerance and inhibit further progression of diabetes. Hence, these animals are useful in studying many aspects of human obese Type II diabetes.

Postprandial hyperglycaemia after an oral glucose load was observed in 8-week-old OLETF rats, although the fasting plasma glucose concentration did not differ between OLETF and the control LongEvans Tokushima Otsuka (LETO) rats [16]. It has been reported, however, that the insulin-induced in vivo glucose utilization is not significantly reduced in OLETF rats until the age of 10 weeks [19]. Furthermore, both the fasting immunoreactive insulin (IRI) concentrations and the concentrations after the oral glucose load are similar in 8-week-old OLETF and LETO rats [16]. The structure and insulin content in the islets are normal in OLETF rats [16].

To investigate the postprandial hyperglycaemia in the early growing stage of OLETF rats, we used the oral D-xylose loading test (OXT) as a pivotal marker of efficacy of the intestinal glucose absorption, which is not affected by either insulin secretion or insulin resistance. The OXT has been used as a clinical test of intestinal absorptional function for malabsorptional diseases [20]. We evaluated whether the efficacy of glucose absorption could be estimated by OXT and we assessed the increased efficacy of intestinal glucose absorption and postprandial hyperglycaemia in OLETF rats. We also examined OXT in 6-week-old
Table 1. Characteristics of the experimental rats

\begin{tabular}{lcc}
\hline & LETO & OLETF \\
\hline Body weight (4-week-old) (g) & $71.5 \pm 1.6$ & $68.7 \pm 0.4$ \\
Body weight (6-week-old) (g) & $172.2 \pm 1.3$ & $173.7 \pm 1.0$ \\
FPG (mmol/l) & $3.6 \pm 0.4$ & $4.0 \pm 0.4$ \\
IRI (pmol/l) & $63.3 \pm 3.2$ & $80.0 \pm 27.1$ \\
Triglycerides (mmol/l) & $0.71 \pm 0.08$ & $0.90 \pm 0.05$ \\
Cholesterol (mmol/l) & $2.1 \pm 0.1$ & $3.2 \pm 0.3^{\mathrm{a}}$ \\
\hline
\end{tabular}

Data are expressed as means \pm SEM. $(n=12)$. FPG, fasting plasma glucose; IRI, immunoreactive insulin. ${ }^{\mathrm{a}} \mathrm{p}<0.01$ vs LETO

OLETF rats which did not show insulin resistance and impaired insulin secretion compared with that in pair-fed LETO rats. Furthermore, we examined the effects of phlorizin, an inhibitor of SGLT1 [9], on plasma glucose and xylose concentration after each oral loading. We also studied the morphological analyses and intestinal SGLT1 mRNA content to characterize xylose absorption in OLETF rats.

\section{Materials and methods}

Animals. Tokushima Institute, Otsuka Pharmaceutical (Tokushima, Japan) kindly provided 4-week-old male OLETF rats and non-diabetic control male LETO rats of similar weight (Table 1). The animals were fed a standard laboratory chow ( $25 \mathrm{~g} /$ day) until 6 weeks of age and kept at controlled temperature $\left(23 \pm 2{ }^{\circ} \mathrm{C}\right)$, humidity $(55 \pm 5 \%)$ and lighting (08.00 to 20.00 hours) in our animal facility. They were used in the following studies after fasting for at least 12 hours.

Oral glucose tolerance test (OGTT). D-glucose $(2 \mathrm{~g} / \mathrm{kg}$ body weight) was given to the animals. A D-glucose solution $(50 \%$ w/v) was given orally with a stainless oro-gastric catheter to conscious animals. Blood samples were drawn with 26-gauge syringes from the jugular vein of conscious rats which were fixed on a special device during each blood sampling at preOGTT and at 30, 60, 90 and $120 \mathrm{~min}$. The plasma glucose concentrations were measured by the glucose oxidase method. The plasma IRI concentrations were determined with a rat insulin enzyme-immunoassay kit (Morinaga, Tokyo, Japan). The rats also received phlorizin $(0.4 \mathrm{~g} / \mathrm{kg}$ body weight $)$. Phlorizin (Tokyo-kasei, Tokyo, Japan) was mixed with the glucose solution and given simultaneously. Plasma glucose and IRI concentrations were also determined. Incremental area under the curves (AUCs) of plasma glucose and IRI concentrations were calculated.

Oral D-xylose loading test $(O X T)$. D-xylose $(0.8 \mathrm{~g} / \mathrm{kg}$ body weight) was given to the animals. A D-xylose solution $(20 \%$ $\mathrm{w} / \mathrm{v}$ ) was given orally with or without $0.4 \mathrm{~g} / \mathrm{kg}$ body weight phlorizin and blood samples were drawn at pre-OXT and at 60, 120, 180 and $240 \mathrm{~min}$ as described in the OGTT method. Plasma xylose concentrations were spectrophotometrically measured as described by Roe and Rice [21]. Plasma glucose and IRI concentrations were also measured as described above.

Intravenous D-xylose loading test (IVXT). D-xylose $(2 \mathrm{~g} / \mathrm{kg}$ body weight) was injected into the animals (LETO, OLETF $n=5$ ) through the tail vein and then blood samples were drawn 
and at at pre-IVXT, 5, 30, 60, 120, and $180 \mathrm{~min}$ from the jugular vein and plasma xylose levels were measured.

In vivo glucose utilization measured by euglycaemic clamp studies. In vivo glucose utilization was obtained by the hyperinsulinaemic-euglycaemic clamp method as described previously $[17,19]$. After the animals (LETO, OLETF $n=5$ ) were anaesthetized by an intraperitoneal injection of pentobarbital ( $50 \mathrm{mg} / \mathrm{kg}$ body weight), catheters were inserted into the jugular and femoral veins. The rats received an insulin infusion $\left(70 \mathrm{pmol} \cdot \mathrm{kg}^{-1} \cdot \mathrm{min}^{-1}\right)$ for $1 \mathrm{~h}$. The infusion rate of the glucose solution $(20 \%)$ was adjusted to the target plasma glucose concentration of $5 \mathrm{mmol} / \mathrm{l}$. Throughout the clamp study, blood samples were drawn every $3 \mathrm{~min}$ from the femoral catheter and the plasma glucose concentrations were monitored for $60 \mathrm{~min}$. Total-body glucose utilization was calculated as the mean value of the glucose infusion rate (GIR) during the last $20 \mathrm{~min}$. Plasma insulin concentrations at $60 \mathrm{~min}$ were measured as steady-state plasma insulin (SSPI) levels.

Morphological analyses and preparation of intestinal samples. After fasting, rats (LETO, OLETF $n=5$ ) were anaesthetized with an intraperitoneal injection of pentobarbital $(50 \mathrm{mg} / \mathrm{kg}$ body weight). The whole small intestines from the pylorus to the ileum end were extracted quickly and stripped of their mesenteries. The intestinal lumina were washed gently with $150 \mathrm{ml}$ of $0.1 \mathrm{~mol} / \mathrm{l}$ phosphate-buffered saline (PBS) and blown with $50 \mathrm{ml}$ of the air to remove PBS. The intestines were then placed on papers to remove PBS from the outer surfaces and their wet weights were measured. Afterwards they were transferred onto tracing papers, divided into four equal segments, and each segment was incised along its mesenteric insertion and laid flat with the mucosal side face up. The outline of each segment was traced and the surface areas and lengths of the whole intestine were measured by a computed image analyzing system (Type IBAS I; Kontron Inc., Munich, Germany). To measure the SGLT1 mRNA content in intestinal tissue, segments $(5 \mathrm{~cm}$; approximately $500 \mathrm{mg})$ were excised quickly from the middle region of the duodenum, jejunum and ileum and the mucosa was immediately subjected to RNA extraction.

Histology. Paraffin sections $(2 \mu \mathrm{m})$ of the paraformalin-fixed small intestines were obtained from the duodenum, jejunum and ileum and stained with Hematoxylin-Eosin. Microscopical analyses were done in four rats of each strain. Ten villi were measured in each part of intestine.

Cloning and sequencing of rat SGLT1 cDNA. Rat SGLT1 cDNA was synthesized with Avian Myeloblastosis Virus reverse transcriptase (Life Science, St. Petersburg, Fla., USA) and polymerase chain reaction (PCR) 3 ' primer using $10 \mu \mathrm{g}$ of rat jejunal total RNA as a template. The cDNA was amplified by PCR with Taq DNA polymerase (TaqPlus, STRATAGENE, La Jolla, Calif., USA) and gene-specific PCR primer. The genespecific PCR primers were designed from the rat SGLT1 cDNA sequence [22]; PCR 5' primer (base 1279-1297 of rat SGLT1) 5 '-GTGGTACC CGTCATGATGGCTTCCCTC (KpnI site italicized), PCR 3' primer (base 2073-2088 of rat SGLT1) 5'GGTCTAGA AGGAGGATGATGCCGT (XbaI site italicized). The reaction mixture was denatured at $94^{\circ} \mathrm{C}$ for $1 \mathrm{~min}$, annealed at $55^{\circ} \mathrm{C}$ for $45 \mathrm{~s}$, and polymerized at $72^{\circ} \mathrm{C}$. Forty cycles were done, followed by a 10 -min extension at $72^{\circ} \mathrm{C}$. The PCR product was directly cloned into pCR II TA clone (Invitrogen, San Diego Calif., USA) and sequenced by the dideoxynucleotide termination method. The rat SGLT1 c DNA inserted vector was digested with EcoRI and used for hybridization.
RNA extraction and Northern blotting. Total RNA was isolated by single-step acid guanidium thiocianate-phenol-chloroform extraction from the duodenal, jejunal and ileal mucosa by the method of Chomczynski and Sacchi [23]. For Northern blotting, $12 \mu \mathrm{g}$ aliquots of total RNA were resolved by electrophoresis on $1.0 \%$ agarose-formaldehyde gels. The RNA was transferred to Nytran filters (NY13; Schleicher \& Schuell, Dassel, Germany) by overnight blotting in a $10 \times$ sodium-chloride citrate (SSC) and fixed with a UV cross-linker (STRATAGENE). The filters were pre-hybridized for $2 \mathrm{~h}$ at $65^{\circ} \mathrm{C}$ in a solution containing $0.5 \mathrm{~mol} / 1 \mathrm{Na}_{2} \mathrm{HPO}_{4}, 1 \%$ bovine serum albumin, $1 \mathrm{mmol} / 1$ EDTA, and $7 \%$ SDS. Hybridization was carried out using the rat SGLT1 cDNA probe labelled with $\left[\alpha-{ }^{32} \mathrm{P}\right]$ dCTP (New England Nuclear, Boston, Mass., USA) using a random primer labelling kit (Buca Best labelling kit; Takara Shuzo, Shiga, Japan). After hybridization for $18 \mathrm{~h}$ at $65^{\circ} \mathrm{C}$, the filters were washed in $0.1 \% \mathrm{SDS}-2 \times \mathrm{SSC}$ for $20 \mathrm{~min}$ and twice in $0.1 \% \mathrm{SDS}-0.2 \times \mathrm{SSC}$ for $20 \mathrm{~min}$ at $65^{\circ} \mathrm{C}$. The filters were exposed to films (Kodak X-mat, Eastman Kodak, Rochester, N. Y., USA) and analysed by a Molecular Analyser system (Bio-Rad Laboratory, Hercules, Calif., USA). Positive bands of SGLT1 mRNA were observed at 4.0 kilo base-pairs in the duodenum, jejunum, ileum and kidney using our SGLT1 cDNA probe as reported previously [22] (data not shown). Control hybridization was done with human $\beta$-actin cDNA (Clontech Laboratory, Palo Alto, Calif., USA).

Statistical analyses. All results were subjected to one way analysis of variance or Student's $t$-test. All data are expressed as the means \pm SEM, and $p<0.05$ was considered statistically significant.

\section{Results}

Characteristics of animals. Animals were fed daily the same amount of standard chow from the age of 4 weeks to eliminate hyperphagia in OLETF rats due to pair-feeding between LETO and OLETF rats. Body weights were similar between OLETF and LETO rats at the age of 6 weeks. The fasting plasma concentrations of glucose and IRI were not considerably different between the two strains, respectively (Table 1). Mean plasma triglyceride concentration in OLETF rats was not different from that in LETO rats. On the other hand, plasma cholesterol concentrations in OLETF rats were significantly $(p<0.01)$ higher than those in LETO rats (Table 1$)$.

OGTT with or without co-administration of phlorizin. In OGTT, 6-week-old OLETF rats showed postprandial hyperglycaemia after the oral glucose load compared with pair-fed LETO rats (Fig. $1 \mathrm{a}, \mathrm{b}$ ). The mean value of plasma glucose at $60 \mathrm{~min}$ of OGTT in OLETF rats $(16.8 \pm 0.9 \mathrm{mmol} / \mathrm{l})$ was higher than that in LETO rats $(10.6 \pm 1.0 \mathrm{mmol} / \mathrm{l})$. The incremental AUC of plasma glucose in OLETF rats $(42.2 \pm 2.9 \mathrm{mmol} / \mathrm{l} \cdot \mathrm{h})$ was also higher than that in LETO rats $(30.4 \pm 1.3 \mathrm{mmol} / \mathrm{l} \cdot \mathrm{h}: \quad p<0.01$ vs OLETF). The IRI levels at 60 or 120 min were similar between the two strains. The IRI levels at $30 \mathrm{~min}$ in LETO vs OLETF were $236 \pm 27 \mathrm{pmol} / \mathrm{l}$ vs $315 \pm 57$ 
pmol/l. The incremental AUCs of IRI were the same between the two strains $(459.1 \pm 52.6 \mathrm{pmol} / \mathrm{l} \cdot \mathrm{h}$ vs $529.6 \pm 85.7 \mathrm{pmol} / \mathrm{l} \cdot \mathrm{h}$; LETO vs OLETF). Therefore, OLETF rats showed postprandial hyperglycaemia without abnormal elevation of IRI concentrations compared with pair-fed LETO rats.

By giving $0.4 \mathrm{~g} / \mathrm{kg}$ phlorizin (Fig. $1 \mathrm{c}, \mathrm{d}$ ) at the same time, the postprandial hyperglycaemia was remarkably inhibited at $30 \mathrm{~min}$ in both strains ( $91 \%$ suppression in LETO and $95 \%$ suppression in OLETF rats) and slight elevations in plasma glucose concentrations at 90 and $120 \mathrm{~min}(p<0.05)$ were observed in OLETF rats. Meanwhile, the plasma IRI levels were kept within the pre-loading concentrations.

In vivo glucose utilization. To clarify whether insulin resistance contributed to hyperglycaemia after the oral glucose load in the 6 week-old OLETF rats, we did hyperinsulinaemic-euglycaemic clamp studies to measure the in vivo glucose utilization. Insulin-induced glucose utilization in vivo in 6-weekold OLETF rats was similar to that in LETO rats (GIR $122 \pm 7 \mu \mathrm{mol} \cdot \mathrm{kg}^{-1} \cdot \mathrm{min}^{-1}$ vs $129 \pm 14 \mu \mathrm{mol}$. $\mathrm{kg}^{-1} \cdot \mathrm{min}^{-1}$; LETO vs OLETF) with a similar steady-state plasma insulin (SSPI) concentration $(5.72 \pm 0.85 \mathrm{nmol} / 1$ vs $4.59 \pm 0.92 \mathrm{nmol} / \mathrm{l} ;$ LETO vs OLETF).

OXT with or without co-administration of phlorizin. To confirm the increased intestinal glucose absorption in OLETF rats, we carried out OXT to evaluate the efficacy of the intestinal glucose absorption (Fig. 2a). We also did the OXT by giving phlorizin at the same time to confirm that OXT could mimic the efficacy of glucose absorption (Fig. 2b).

As previously shown, the peak concentrations of plasma xylose in OXT were obtained between 60 and 150 min in human subjects [20]. Similarly, the peak plasma xylose levels in OLETF rats were obtained at either 60 or $120 \mathrm{~min}$ and were noticeably higher than those of the control rats. The mean value at $60 \mathrm{~min}$ was $3.10 \pm 0.18 \mathrm{mmol} / \mathrm{l}$ in OLETF rats (vs LETO, $p<0.005)$ and $1.95 \pm 0.3 \mathrm{mmol} / 1$ in LETO rats. The AUC of the plasma xylose concentrations during the 4-h OXT was also increased in OLETF rats $(3.35 \pm 0.29 \mathrm{mmol} / \mathrm{l} \cdot \mathrm{h}$ vs $5.05 \pm 0.58 \mathrm{mmol} / \mathrm{l} \cdot \mathrm{h}$; $p<0.05$ vs LETO). The values in pre-OXT were the same for the two strains. Oral treatment with xylose did not affect the plasma glucose or IRI concentrations at all (data not shown).

We carried out OXT by giving phlorizin $(0.4 \mathrm{~g} / \mathrm{kg}$ body weight) at the same time. As shown in Fig. 2 b, the plasma xylose concentrations were not elevated in the two strains during this OXT. Therefore, we assumed that the plasma xylose concentrations in OXT mimicked the efficacy of glucose absorption since phlorizin inhibited the elevation of plasma xylose concentrations.
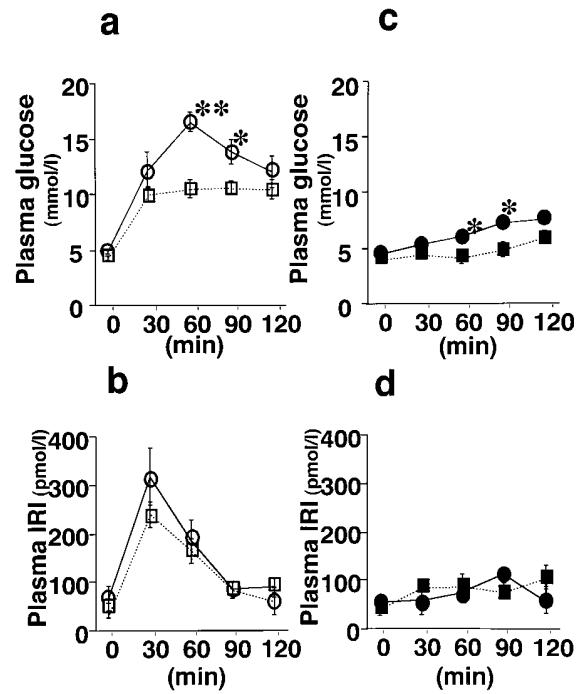

Fig. 1. Oral glucose tolerance test without $(\mathbf{a , b})$ and with $(\mathbf{c}, \mathbf{d})$ co-administration of phlorizin $(0.4 \mathrm{~g} / \mathrm{kg}$ body weight). D-glucose $(2 \mathrm{~g} / \mathrm{kg}$ body weight $)$ was given LETO rats (open and closed squares; $n=5$ ) and OLETF (open and closed circles; $n=5)$ rats. (a)(c) plasma glucose concentration, (b)(d) plasma IRI concentration. Values are expressed as means \pm SEM. $* p<0.05, * * p<0.01$ vs LETO rats

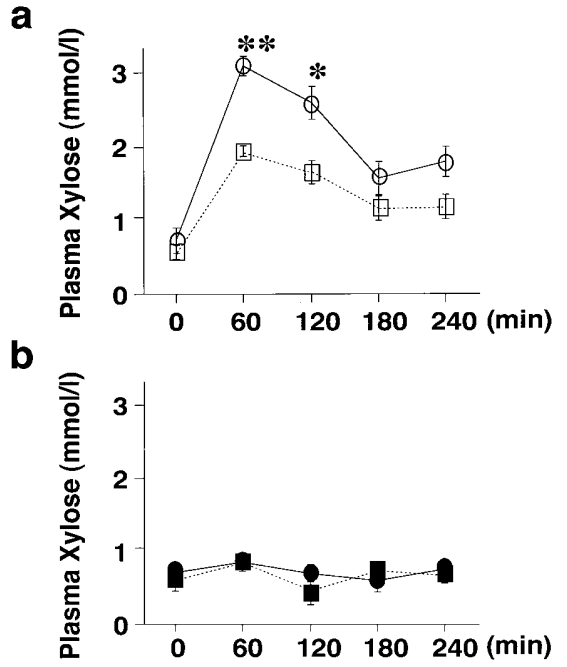

Fig. 2. Oral D-xylose loading test $(0.8 \mathrm{~g} / \mathrm{kg}$ body weight $)$ without (a) and with (b) co-administration of phlorizin $(0.4 \mathrm{~g} / \mathrm{kg}$ body weight). LETO (open and closed squares; $n=5$ ) and OLETF (open and closed circles; $n=5$ ) rats. Values are expressed as means \pm SEM. $* p<0.01, * * p<0.005$ vs LETO rats

Intravenous xylose loading test (IVXT). To exclude the possibility that increased xylose concentrations in OLETF rats were mediated through a decreased clearance of xylose by unknown reasons, we next determined the disappearance rate of plasma xylose after intravenous xylose injection $(0.2 \mathrm{~g} / \mathrm{kg}$ body weight) in both strains.

The plasma xylose concentrations were raised similarly in both strains after injection of the xylose solution $(4.02 \pm 0.41 \mathrm{mmol} / \mathrm{l}$ vs $5.12 \pm 0.36 \mathrm{mmmol} / \mathrm{l}$ at 
5 min; LETO vs OLETF) and decreased at a similar disappearance rate $(2.36 \pm 0.22 \mathrm{mmol} / \mathrm{l}$ vs $1.84 \pm$ $0.62 \mathrm{mmol} / \mathrm{l}$ at $30 \mathrm{~min}, 0.97 \pm 0.04 \mathrm{mmol} / \mathrm{l}$ vs $1.11 \pm$ $0.05 \mathrm{mmmol} / 1$ at $60 \mathrm{~min}, 0.49 \pm 0.11 \mathrm{mmol} / 1$ vs $0.36 \pm$ $0.19 \mathrm{mmol} / \mathrm{l}$ at $120 \mathrm{~min}, 0.29 \pm 0.05 \mathrm{mmol} / 1$ vs $0.21 \pm$ $0.01 \mathrm{mmol} / \mathrm{l}$ at $180 \mathrm{~min}$; LETO vs OLETF). The plasma half-life of xylose $\left(\mathrm{T}_{1 / 2}\right)$ did not differ between the two strains $(29.3 \pm 1.7 \mathrm{~min}$ vs $27.6 \pm 1.1 \mathrm{~min}$; LETO vs OLETF). Thus, these findings indicate that xylose is similarly cleared from the plasma in both stains.

Morphological study. Based upon the results of the OXT and IVXT, the small intestine may contribute to hyperabsorption of glucose and xylose in OLETF rats. To confirm this evidence, we compared the morphological parameters of the small intestine in the two strains.

The intestinal wet weight, length and area in OLETF rats were considerably larger than those in LETO rats although the influence of hyperphagia in OLETF rats was eliminated by pair-feeding (wet weight $5.69 \pm 0.13 \mathrm{~g}$ vs $7.20 \pm 0.08 \mathrm{~g}, p<0.0001$; area $86.6 \pm 3.7 \mathrm{~cm}^{2}$ vs $118.4 \pm 1.4 \mathrm{~cm}^{2}, p<0.005$; length $96.1 \pm 3.4 \mathrm{~cm}$ vs $111.5 \pm 1.0 \mathrm{~cm}, p<0.001$; LETO vs OLETF). The intestinal wet weight and area in OLETF rats were increased 1.27- and 1.37-fold compared with those in LETO rats, respectively, while the mean body weight of OLETF rats was not different from that of LETO rats as shown in Table 1.

We next did a microscopical examinations of the small intestine. Fig. 3 shows the photomicrographic findings of the jejunum and ileum of both strains. In the jejunum, the mucosal layer was hypertrophic in OLETF rats compared with the control tissue. The mean height of villi was $335.0 \pm 8.2 \mu \mathrm{m}$ in LETO rats and $402.5 \pm 2.2 \mu \mathrm{m}$ in OLETF rats $(p<0.001)$. Crypt depth was also enlarged in OLETF rats (115.5 \pm $2.4 \mu \mathrm{m}$ vs $147.0 \pm 4.2 \mu \mathrm{m}$, vs LETO, $p<0.001)$. The ileum of OLETF rats was also enlarged in both villus height and crypt depth compared with that of LETO rats (villus height $245.0 \pm 7.9 \mu \mathrm{m}$ vs $327.5 \pm 6.8 \mu \mathrm{m}$; crypt depth $134.0 \pm 6.2 \mu \mathrm{m}$ vs $185.0 \pm 5.4 \mu \mathrm{m}, p<$ 0.001 LETO vs OLETF). These findings were similarly observed in the duodenum (data not shown).

Expression of sodium-dependent glucose transporter1 (SGLT1). Sugar absorption inhibited by phlorizin is mediated though SGLT1 in the small intestine. That is why we carried out Northern blot analysis and compared the SGLT1 mRNA expression in the small intestine in the two strains. The results of the Northern blot analysis of the jejunum and ileum are shown in Fig. 4 a. The SGLT1 mRNA content in both portions of OLETF rats was greater than that of LETO rats, respectively. The SGLT1 mRNA content in OLETF rats was increased 1.6-fold compared with LETO rats which was adjusted by the $\beta$-actin mRNA content (Fig. 4b) $(p<0.05)$.
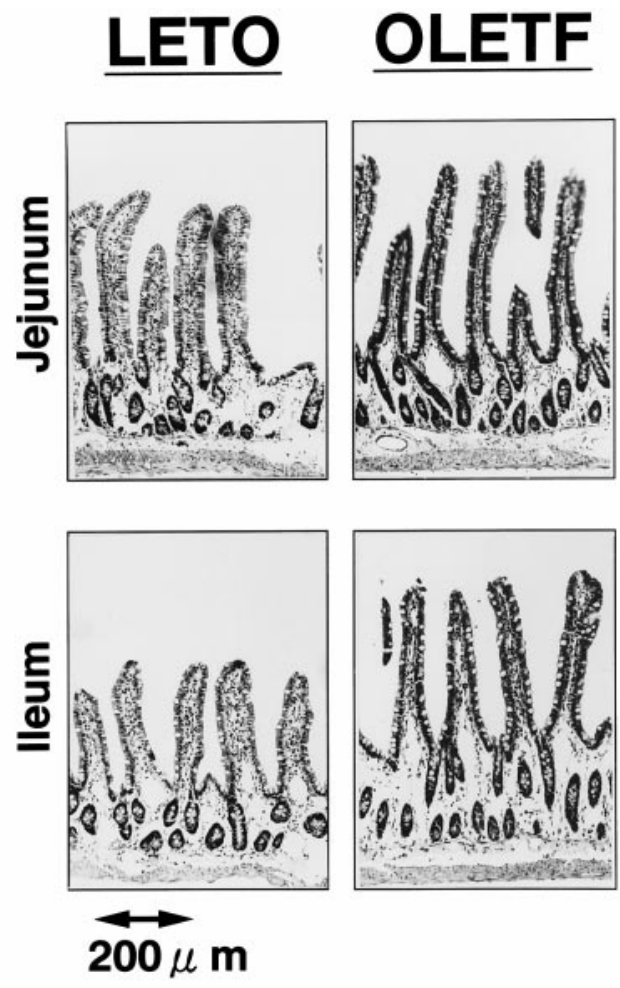

Fig.3. Photomicrography of small intestine. Longitudinal section of jejunum and ileum. Magnification is $\times 80$. LETO (left side), OLETF (right side). Upper and lower panels show jejunum and ileum, respectively. Bar indicates $200 \mu \mathrm{m}$
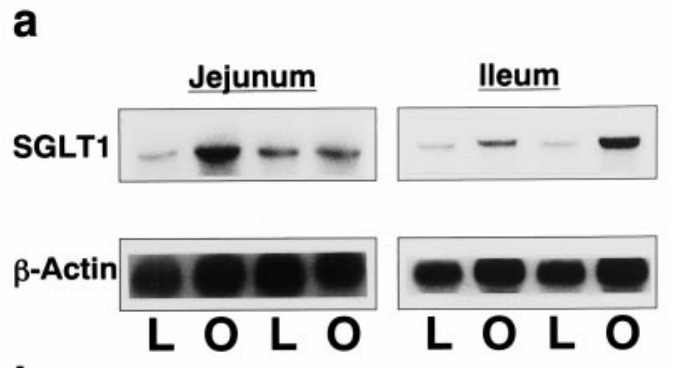

b

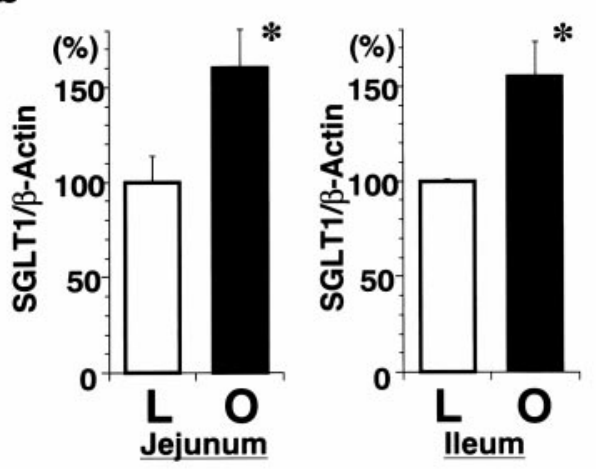

Fig. 4. SGLT1 mRNA content in small intestine in 6-weekLETF and OLETF rats. (a) SGLT1 mRNA (upper panels) and $\beta$-actin mRNA (lower panels) contents in jejunum (left panels) and ileum (right panels). (b) Quantitative data of relative intensity (SGLT1 mRNA/ $\beta$-actin mRNA: LETO $n=4$, OLETF $n=4)$. Data are expressed as percentage of the LETO values in relative intensity. Bars are expressed as means \pm SEM. $* p<0.05$ vs LETO 


\section{Discussion}

In this study, we used 6-week-old OLETF rats which showed postprandial hyperglycaemia but did not have insulin resistance and impaired insulin secretion. Our study showed that these animals at this age had intestinal hypertrophy, an increased content of SGLT1 mRNA in intestinal epithelial cells and increased efficacy of glucose absorption before developing overt diabetes mellitus. It suggests also that the increased efficacy of glucose absorption could contribute to postprandial hyperglycaemia in this study animal.

Six-week-old OLETF rats developed fasting euglycaemia and postprandial hyperglycaemia after the oral glucose load in comparison with LETO rats although both strains showed similar plasma insulin concentrations. Ishida et al. reported [19] that plasma IRI concentrations after either an intravenous glucose or glucagon load were not different between the two strains at both 10 and 16 weeks of age. Therefore, insulin secretion in 6-week-old OLETF rats may be sufficient to maintain fasting euglycaemia but insufficient to correct postprandial hyperglycaemia caused by the excess of intestinal glucose absorption. We infer that increased insulin secretion in response to absorbed glucose was impaired regardless of the insulin resistant state in OLETF rats. The underlying mechanism is unclear in this study. Cholecystokinin (CCK), however, is a candidate of "incretin" which is released from enteroendocrine cells after eating and stimulates insulin secretion. It is possible that an impaired CCK release causes the impaired insulin secretion in OLETF rats. A defective insulin response to intravenous infusion of CCK is reported in OLETF rats [24]. Glucose-dependent insulinotropic peptide (GIP), and glucagon-like peptide 1 (GLP-1) are known as more potent candidates of "incretins" [25]. The inappropriate release of these "incretins" from the intestine in response to the oral glucose treatment should be further evaluated to explain the insufficient insulin secretion from $\beta$ cells in OLETF rats.

Our results showed also that there were no differences in glucose utilization in vivo. These were measured by hyperinsulinaemic-euglycaemic clamp method with similar steady-state plasma insulin concentrations between the two strains as reported previously in 10-week-old animals [19]. The insulin secretion after an oral glucose load was also similar in 6week-old OLETF and LETO rats. Both insulin deficiency and decreased peripheral glucose utilization could not explain the appearance of postprandial hyperglycaemia in OLETF rats of this age. Hepatic glucose output might contribute to postprandial hyperglycaemia in this model animal as reported in Zucker diabetic rats [26]. It is unlikely, however, that the hepatic glucose output in OLETF rats was increased compared with that in LETO rats since the fasting
IRI level as well as the insulin-induced in vivo glucose utilization was the same in the two strains in this study. The glucagon concentrations are also reported to be similar in young LETO and OLETF rats [19, 27]. Thus, we hypothesize that the increment in intestinal glucose absorption may contribute to the postprandial hyperglycaemia in OLETF rats.

To clarify the contribution of intestinal glucose absorption to postprandial hyperglycaemia, we used xylose in this study as a clinical marker for intestinal absorption. Plasma xylose concentrations were noticeably elevated in OLETF rats after the oral xylose load compared with LETO rats. When xylose was given intravenously, the disappearance rate of the plasma xylose concentrations in the 6-week-old pairfed OLETF rats was the same as that in the control LETO rats. Shoji et al. [28] reported that gastric emptying is delayed in 7-week-old OLETF rats. Delayed gastric emptying could delay and decrease the peak plasma values of xylose in OXT [20]. In our study, the peak values were not delayed and were obtained at $60 \mathrm{~min}$ in the two strains. The values in OLETF rats were increased compared with LETO rats. Hence, intestinal xylose absorption in OLETF rats was increased compared with LETO rats without any difference in the plasma disappearance or gastric emptying rates.

To ascertain that xylose absorption was mimicking the efficacy of intestinal glucose absorption, we examined the effect of phlorizin on OGTT and OXT when given at the same time. Phlorizin suppressed both increased plasma glucose and xylose concentrations after each oral load in our study. Glucose uptake is mediated through SGLT1 at the apical membrane of absorptive enterocytes and phlorizin inhibits the SGLT1-mediated glucose transport. After the absorption into the enterocytes, glucose is facilitatively transported out of the basolateral site through GLUT2 without inhibition by phlorizin [9]. Although there were some discrepancies between xylose and glucose absorption [29,30], xylose transport is reported to be mediated through a similar mechanism of glucose in the rat and rabbit $[31,32]$. It has also been reported that xylose transport is inhibited by phlorizin in the inverted intestine of hamsters [33]. Our results that phlorizin inhibited the increase of plasma xylose concentrations in OLETF rats and in LETO rats also support the hypothesis that intestinal glucose absorption through SGLT1 is enhanced in OLETF rats.

Next we investigated the SGLT1 expression in the animals. We showed that the SGLT1 mRNA contents of the jejunum and ileum were increased more in OLETF rats than in LETO rats. It has been reported that a high carbohydrate diet induces SGLT1 mRNA expression in a substrate-dependent manner [10]. The increment in intestinal SGLT1 mRNA in OLETF rats was considered to be independent of di- 
etary intake of carbohydrate since our study was undertaken in pair-feeding conditions. Both the SGLT1 and GLUT2 expression of the mRNA and protein contents were reported to be increased in the small intestine of streptozotocin-treated diabetic rats concomitant with increased glucose transport [34, 35]. Although insulin deficiency, hyperphagia and hyperglycaemia could contribute to an increased expression of SGLT1 in those rats, the mechanism of the increased expression of transporters is unclear [35]. Therefore, the mechanism of the abnormal expression of SGLT1 mRNA in the small intestine of OLETF rats should be further investigated in future studies.

Intestinal hyperplasia is reported in streptozotocin-treated diabetic rats with increased intestinal glucose absorption [12-14]. Our results indicated that the intestinal hypertrophy was observed in 6-weekold OLETF rats which showed postprandial hyperglycaemia with normal fasting plasma glucose and insulin concentrations. It has been noted in OLETF rats that a CCK-A receptor is genetically affected because of the gene deletion [36] and that the proliferation of pancreatic beta cells is also impaired in regenerative growth [37]. Other diabetogenic genes were screened in those rats and it has recently been reported that the CCK-A receptor gene is found to be similar to one of these genes, OBD-2 gene, by a linkage analysis using microsatellite markers [38]. These genetic abnormalities could influence intestinal hypertrophy in OLETF rats. CCK is known, however, to stimulate intestinal mucosal mass growth due to pancreatic and bile secretions [39]. It is unclear whether a defect in the CCK-A receptor in OLETF rats is associated with intestinal hypertrophy.

In conclusion, intestinal glucose absorption through SGLT1 was increased and was accompanied by intestinal epithelial hypertrophy and an increased intestinal epithelial SGLT 1 mRNA content in 6week-old OLETF rats. Our results suggest that the increased intestinal glucose absorption is associated with postprandial hyperglycaemia before the onset of insulin resistance and hyperinsulinaemia in these obese Type II diabetic rats.

Acknowledgements. This work was supported in part by grants from the Ministry of Education Science and Culture of Japan and the Shiga Medical Science Association for International Cooperation.

\section{References}

1. Reaven GM (1988) Banting Lecture 1988: role of insulin resistance in human disease. Diabetes 37: 1595-1607

2. De Fronzo RA (1992) Pathogenesis of type 2 (non-insulindependent) diabetes mellitus: a balance overview. Diabetologia 35: 389-397

3. Leahy JL (1990) Natural history of beta cell dysfunction. Diabetes Care 13: 992-1010
4. Henry RR, Wallance P, Olefsky JM (1986) Effect of weight loss on mechanism of hyperglycemia in obese non-insulindependent diabetes mellitus. Diabetes 35: 990-998

5. Wing RR, Blair EH, Bononi P, Marcus MD, Watanabe R, Bergman RN. (1994) Caloric restriction per se is a significant factor in improvement in glycemic control and insulin sensitivity during weight loss in obese NIDDM patients. Diabetes Care 17: 30-36

6. Samad AHB, Willing TST, Albelti KGMM, Taylor R (1988) Effect of BAY m 1099, new $\alpha$-glucosidase inhibitor, on acute metabolic responses and metabolic control in non insulin-dependent diabetes over 1 month. Diabetes Care 11: 337-344

7. Chiasson JL, Josse RG, Wolever TM et al. (1996) The effect of acarbose on insulin sensitivity in subjects with impaired glucose tolerance. Diabetes Care 19: 1190-1193

8. Ferraris RP, Diamond J (1997) Regulation of intestinal sugar transport. Physiological Reviews 77: 257-302

9. Hediger MA, Rhoads DA (1994) Molecular Physiology of Sodium-Glucose cotransporter. Physiological Reviews 74: 993-1026

10. Miyamoto K, Hase K, Takagi Tet al. (1993) Differential responses of intestinal glucose transporter mRNA transcript to levels of dietary sugars. Biochem J 295: 211-215

11. Dyer J, Barker PJ, Shirazi-Beechey SP (1997) Nutrient regulation of the intestinal $\mathrm{Na}^{+}$/Glucose co-transporter (SGLT1) gene expression. Biochem Biophys Res Commun 230: 624-629

12. Kojima H, Omoto Y, Hidaka H et al. (1993) Increased post-heparin diamine oxidase activity and plant sterol levels in streptozotocin diabetic rats. Biochem Biophys Res Commun 186: 398-404

13. Schedl HP, Wilson HD (1971) Effect of diabetes on intestinal growth and hexose transport in the rat. J Physiol 220: 1739-1745

14. Fedorak RN, Chang EB, Field M (1987) Intestinal adaptation to diabetes. Altered Na-dependent nutrient absorption in streptozotocin-treated chronically diabetic rats. J Clin Invest 79: 1571-1578

15. Kojima H, Hidaka H, Matsumura K et al. (1998) Concerted regulation of enterocyte differentiation by insulin-like growth factor I, insulin and transforming growth factor $\beta 1$. Proc Assoc Am Physicians 110: 197-206

16. Kawano K, Hisahara T, Mori S, Saitoh Y, Kurosumi M, Natori T (1992) Spontaneous long-term hyperglycemic rat with diabetic complications. Diabetes 41: 1422-1428

17. Shima K, Shi K, Mizuno A, Sano T, Ishida K, Noma Y (1996) Exercise training has a long-lasting effect on prevention of non-insulin-dependent diabetes mellitus in OtsukaLong-Evans-Tokushima Fatty rats. Metabolism 45: 475-480

18. Okauchi N, Mizuno A, Yoshimoto S, Zhu M, Sano T, Shima K (1995) Is caloric restriction effective in preventing diabetes mellitus in Otsuka Long Evans Tokushima Fatty rats, a model of spontaneous non-insulin-dependent diabetes mellitus? Diabetes Res Clin Pract 27: 97-106

19. Ishida K, Mizuno A, Zhu M, Sano T, Shima K (1995) Which is the primary etiologic event in Otsuka Long-Evans Tokushima Fatty rats, a model of spontaneous non-insulindependent diabetes mellitus, insulin resistance, or impaired insulin secretion? Metabolism 44: 940-945

20. Craig RM, Atkinson AR (1988) D-Xylose Testing: A Review. Gastroenterology 95: 223-231

21. Roe HJ, Rice EW (1948) A photometric method for determination of free pentoses in animal tissue. J Biol Chem 173: 507-512 
22. Lee WS, Kanai Y, Hediger M (1994) The high affinity $\mathrm{Na}+$ /glucose transporter, re-evaluation of function and distribution of expression. J Biol Chem 269: 12032-12039

23. Chomczynski P, Sacchi N (1987) Single-step method of RNA isolation by acid guanidium thiocyanate-phenolchloroform extraction. Anal Biochem 162: 156-165

24. Tachibana I, AkiyamaT, Kanagawa K et al. (1996) Defect in pancreatic exorine and endocrine response to CCK in genetically diabetic OLETF rats. Am J Physiol 270: G730-G737

25. Drucker DJ (1998) Glucagon-like peptides. Diabetes 47: 159-169

26. Rohner-Jeanrenaud F, Proietto J, Inonescu E, Jeanrenaud B (1986) Mechanism of abnormal oral glucose tolerance of genetically obese fa/fa rats. Diabetes 35: 1350-1355

27. Hotta K, Kuwajima M, Ono A et al. (1996) Disordered expression of hepatic glycolytic and gluconeogenic enzymes on Otsuka Long-Evans Tokushima fatty rats with spontaneous long-term hyperglycemia. Biochim Biophys Acta 1289: $145-149$

28. Shoji E, Okumura T, Onodera S, Takahashi N, Harada K, Kohgo Y (1997) Gastric emptying in OLETF rats not expressing CCK-A receptor gene. Dig Dis Sci 42: 915-919

29. Fordran JS, Soergel KH, Ingelfinger FJ (1962) Intestinal absorption of D-xylose in man. N Engl J Med 267: 274-279

30. Cook GC (1977) Rates and mechanisms of glucose, galactose and xylose absorption in man in vivo. Scand J Gastroenterol 12: 733-737
31. Heyman M, Dumintier AM, Desjeux JF (1980) Xylose transport pathway in the rabbit lleum. Am J Physiol 238: G326-G331

32. Faust RG, Hollifield JW, Leadbetter MG (1967) D-Xylose active intestinal transport in a sodium iron substituted lithium medium. Nature 267: 1297-1298

33. Alvarado F (1967) Hypothesis for the interaction of phlorizin and phloretin with membrane carriers for sugars. Biochim Biophys Acta 135: 483-495

34. Miyamoto K, Hase K, Taketani Y et al. (1991) Diabetes and glucose transporter gene expression in rat small intestine. Biochem Biophy Res Commun 181: 1991

35. Burant CF, Flink S, Depaoli AM et al. (1994) Small intestine hexose transport in experimental diabetes. J Clin Invest 93: 578-585

36. Takiguchi S, Takata Y, Funakoshi A et al. (1997) Disrupted cholecystokinin type-A receptor (CCKAR) gene in OLETF rats. Gene 197: 169-175

37. Zhu M, Noma Y, Shima K, Mizuno A, Sano T, Shima K (1996) Poor capacity or proliferation of pancreatic B-cells in Otsuka Long-Evans Tokushima Fatty: a model of spontaneous NIDDM. Diabetes 45: 941-964

38. Takiguchi S, Takata Y, Takahashi N (1998) A disrupted cholecystokinin A receptor induces diabetes in obese rats synergistically with ODB1 gene. Am J Physiol 274 (2 Pt 1): E265-E270

39. Fine H, Levine GM, Shiau YF (1982) Effect of cholecystokinin and secretin on intestinal structure and function. Am J Physiol 245: G358-G363 